\title{
Hybrid damage prediction procedure for composite laminates submitted to spectra loading
}

\author{
M OHAMMED BOUSFIA $^{1 *}$, M OHAMMED ABOUSSALEH $^{1}$ AND B RAHIM $_{\text {OUHBI }}{ }^{2}$ \\ Department of mechanical engineering and structures, M2I \\ ${ }^{2}$ Department of industrial and production engineering, ModEC \\ University of Moulay Ismail \\ National School of Arts and Crafts (ENSAM). Meknès, Marjane II, Beni Mhamed. \\ MOROCCO
}

\begin{abstract}
In this document, a hybrid procedure is constructed in order to predict the damage of a composite unidirectional laminate under random loading. This procedure is based on two pillars: a stiffness degradation model (SD-M) combined with an energy approach taking into account the effect of load ratio in addition to a system of equations generated by SSDQM method (Space State Differential Quadrature Method) which we have solved with a novel technic. The outputs of SSDQM method, previously serving for free vibration behavior analysis of composite structures, are used with those of SD-M model to predict damage failure of a composite laminate subjected to spectra loading. The results obtained correlate very well with experimental ones and an extensive comparison with other models validate the accuracy and convergence characteristics of this hybrid procedure.
\end{abstract}

Key-Words: - Composite laminate; Spectrum loading; Damage energy; Lifetime prediction; Stiffness degradation; Load ratio.

Received: September 6, 2020. Revised: December 7, 2020. Accepted: December 18, 2020. Published: December 27, 2020

\section{Introduction}

The life of a structure can come to a sudden end or last longer, but only for a limited period. This latter case is usually accompanied by a reduction in yield, known as aging. Under a high load, a structure or component can deteriorate in one fell swoop, while it can actually withstand lower loads. On the other hand, the same structure or component can also be ruined under lower loads if they are applied over longer delays, either constant amplitude (static) or variable amplitude (fatigue). These loadings sustained by the mechanical structures are induced by external stresses (forces, thermal, accelerations, etc.). The phenomenon of degradation of the properties of a material due to the application of loads that fluctuate over time is called fatigue and the resulting ruin is called fatigue failure.

Due to the complexity of fatigue damage process in composite materials, prediction of their fatigue life is of vital importance. But, a proper modeling of the damage evolution is the foundation for predicting the fatigue life of composite structures which enables an appropriate evaluating of structure's performances in its early cycles of life and prevents catastrophic failures. Some authors were based on residual strength or stiffness, Yao and Himmel [1] predict residual strength caused by fatigue damage in glass and carbon fiber reinforced plastics. To predict and investigate the effect of high-stress peaks on fatigue life of carbon fiber reinforced plastics, Aghazadeh and Majidi [2] applied a residual strength. Another stiffness-based model for life prediction of $\mathrm{Wu}$ and Yao researchers [3] is also considered quite well model to predict residual fatigue life of composites. However, predictions of these models are noticeably divergent to experimental values and mostly yield a high percent of error in fatigue life prediction.

In last decades, stiffness-based models [4-7] were another range of models that have been developed. The damage degree is quantified by measuring young's modulus of the material. But, most of these models present especially two major deficiencies, firstly is a high number of parameters which requiring extensive experimental data to calculate them. While the second deficiency is their inability to simulate accurately the damage progress in its well-known three stages [7-9]. Additionally to the aforementioned shortcoming, most of these models 
are validated for a specific typed of composite and are not evaluated in a wide range of loading levels $[1,10,11]$.

On the other hand, vibration analysis of composite structures is also a big area of research encouraging researchers to ensure the usability, durability, and safety during composite structure's lifetime. Many works were conducted in this trend [12-22], a number of models and methods have been developed. Among them stands out state space method combined with differential quadrature method briefly noted SSDQM.

In this paper we aimed to resolve the discussed limitations of stiffness-based models throughout a hybrid damage prediction procedure. It consists of coupling a stiffness-based model with a SSDQM method while relying both on an energy approach for predicting damage rupture [23] and a wellknown Palmgreen Miner rule [24]. In the first place, the SSDQM is solved by a new proposed technic differently to ones found in the literature. Then a coupling algorithm is developed to survey damage progress of the composite laminate and consequently predict their damage rupture. Numerical validation of the hybrid procedure demonstrates that most of the predicted lifetimes lead to quantitatively better estimations.

\section{New technic for solving the SSDQM method}

In their works $[\mathbf{1 4}, \mathbf{1 5}, \mathbf{2 1}]$, authors combined state space method (SSM) [18-20] with differential quadrature method (DQM) [12-14] to establish an equation system (1) and each one proceeds in his own way to solve it.

$$
\frac{\mathrm{d} \Delta}{\mathrm{dz}}=\mathrm{M}^{(\mathrm{k})} \Delta
$$

Where:

$$
\begin{aligned}
& \Delta=\left[\begin{array}{llllll}
Z & U & V & W & T_{x z} & T_{y z}
\end{array}\right]^{T}, \\
& \mathrm{Z}=\left[\begin{array}{llll}
Z_{1} & Z_{2} & \ldots & Z_{N}
\end{array}\right]^{T}, \\
& M^{(k)}=\left[\begin{array}{cc}
0 & M_{1}^{(k)} \\
M_{2}^{(k)} & 0
\end{array}\right], \\
& \mathrm{M}_{1}^{(\mathrm{k})}=\left[\begin{array}{ccc}
-\rho \omega^{2} I & -\mathrm{g}^{(1)} & \lambda_{\mathrm{b}} I \\
-\mathrm{g}^{(1)} & \mathrm{c}_{7} I & 0 \\
-\lambda_{\mathrm{b}} I & 0 & \mathrm{c}_{8} I
\end{array}\right],
\end{aligned}
$$

$$
\mathrm{M}_{2}^{(\mathrm{k})}=\left[\begin{array}{ccc}
\mathrm{c}_{9} I & \mathrm{c}_{1} \mathrm{~g}^{(1)} & -\mathrm{c}_{5} \lambda_{\mathrm{b}} I \\
\mathrm{c}_{1} \mathrm{~g}^{(1)} & \left(\mathrm{c}_{6} \lambda_{\mathrm{b}}^{2}-\rho \omega^{2}\right) \mathrm{I}-\mathrm{c}_{2} \mathrm{~g}^{(2)} & \left(\mathrm{c}_{3}+\mathrm{c}_{6}\right) \lambda_{\mathrm{b}} \mathrm{g}^{(1)} \\
\mathrm{c}_{5} \lambda_{\mathrm{b}} I & -\left(\mathrm{c}_{3}+\mathrm{c}_{6}\right) \lambda_{\mathrm{b}} \mathrm{g}^{(1)} & \left(\mathrm{c}_{4} \lambda_{\mathrm{b}}^{2}-\rho \omega^{2}\right) \mathrm{I}-\mathrm{c}_{6} \mathrm{~g}^{(2)}
\end{array}\right]
$$

The components of the matrix $\Delta$ are vectors defined as the state variables vector $\mathrm{Z} . \mathrm{N}$ is the discretization number, $\mathrm{k}$ significant the $\mathrm{k}^{\text {th }}$ ply of the laminate, $\mathrm{I}$ is the identity matrix and $g_{i j}^{(n)}$ are the weighting coefficients [16] dependent on Chebyshev-GaussLobatto points xi [17]:

$$
x_{i}=\frac{a}{2}\left[1-\cos \frac{(i-1) \pi}{N-1}\right], \quad i=1,2, \ldots, N,
$$

The coefficients $c_{i}$ are defined and given in reference [17] which depends on the elastic material constants, $\rho$ is the mass density and $\omega$ is a circular frequency. While $\lambda_{b}$ is a constant parameter depending on an arbitrary positive integer $\mathrm{n}$ and is expressed as following: $\lambda_{b}=\frac{\pi n}{b}$.

For a specific problem, the boundary conditions at edges $(x=0$ and $x=a)$ of the studied plate must be taken into consideration so that we can have a unique solution of the equation (1). By applying boundary conditions we add a subscript ' $\mathrm{q}$ ' to equation (1) to indicate it:

$$
\frac{\mathrm{d}}{\mathrm{dz}} \Delta_{\mathrm{q}}=\mathrm{M}_{\mathrm{q}}^{(\mathrm{k})} \Delta_{\mathrm{q}}
$$


Explicit expressions of matrix $\mathrm{M}_{1 \mathrm{q}}^{(\mathrm{k})}$ and $\mathrm{M}_{2 \mathrm{q}}^{(\mathrm{k})}$ for each boundary condition case are given in appendix A.

Many methods are envisaged in the literature to solve this system (2), Xu and Ding [22] used algebra rules and Cayley-Hamilton theorem to solve it. Direct use of global transfer matrix is one of the methods found in the literature [15-17] to solve this system. In this work, the global transfer matrix is used also to solve the system (2) but in combination with a Coupling Joint matrix proposed and noted $\mathrm{J}_{\mathrm{C}}$.

The novel technic developed here to solve the expression (2) is consisted on following steps:

- First, the vector of state variables for the ply $\mathrm{k}$ is written as:

$$
\Delta_{\mathrm{i}}^{(\mathrm{k})}=\left\{\begin{array}{c}
\mathrm{Z}_{\mathrm{i}}^{(\mathrm{k})} \\
\mathrm{U}_{\mathrm{i}}^{(\mathrm{k})} \\
\mathrm{V}_{\mathrm{i}}^{(\mathrm{k})} \\
\mathrm{W}_{\mathrm{i}}^{(\mathrm{k})} \\
\mathrm{T}_{\mathrm{xz}_{\mathrm{i}}}^{(\mathrm{k})} \\
\mathrm{T}_{\mathrm{yz}_{\mathrm{i}}}^{(\mathrm{k})}
\end{array}\right\}
$$

Where i take ' 0 ' (inferior face of the ply) or ' 1 ' (superior face of the ply),

- Second, the following formula is supposed to assure the continuity condition between two adjacent plies: $\mathrm{J}_{\mathrm{C}} \cdot\left\{\begin{array}{c}\Delta_{1}^{(k)} \\ \Delta_{0}^{(k+1)}\end{array}\right\}=0$ where $J_{C}=[I-I]$ is named the Coupling Joint matrix. Noting that "I'" is identity matrix with the same dimension as the length of the vector $\Delta$.

- Third, the loading conditions at the superior interface and the inferior one are expressed respectively like:

$J_{\text {sup }} \cdot \Delta_{1}^{m}=f_{\text {sup }}$ and $J_{\text {inf }} \cdot \Delta_{0}^{1}=f_{\text {inf }}$.

The inferior face doesn't submit any mechanical forces where the vector force (stresses) $f_{\text {in }}$ is zero and consequently the matrix $J_{\text {inf }}$ is equal to zero. On the other side, the superior face laminate's is submitted to a bending loading where the vector force $f_{\text {sup }}$ and the matrix $J_{\text {sup }}$ are written as following:

$$
\begin{aligned}
& \mathrm{f}_{\text {sup }}=\left\{\begin{array}{c}
\mathrm{q}_{\text {sup }} \\
0 \\
0
\end{array}\right\} \\
& \mathrm{J}_{\text {sup }}=\left[\begin{array}{cccccc}
\mathrm{i}_{1} & 0 & 0 & 0 & 0 & 0 \\
0 & 0 & 0 & 0 & \mathrm{i}_{5} & 0 \\
0 & 0 & 0 & 0 & 0 & \mathrm{i}_{6}
\end{array}\right]
\end{aligned}
$$

Where $i_{1}, i_{5}$ and $i_{6}$ are the matrix identities having dimensions adequate to the state variables vectors lengths $Z, T_{x z}$ and $T_{y z}$ respectively. We note also that $\mathbf{J}_{\text {inf }}$ matrix dimension is the same as matrix $\mathbf{J}_{\text {sup }}$.

The gathering of all above expressions of joint coupling matrix conduct to the general formula (6):

$$
\mathrm{J} . \Delta=\mathrm{f}
$$

With:

$\mathrm{J}=\operatorname{diag}\left[\mathrm{J}_{\text {inf }} \mathrm{J}_{\mathrm{C}_{1}} \mathrm{~J}_{\mathrm{C}_{2}} \ldots \mathrm{J}_{\mathrm{C}_{\mathrm{m}}} \mathrm{J}_{\text {sup }}\right]$;

$\mathrm{f}=\left[\begin{array}{lllll}\mathrm{f}_{\text {inf }}^{\mathrm{T}} 0_{1} & 0_{2} & \ldots & 0_{\mathrm{m}} \mathrm{f}_{\text {sup }}^{\mathrm{T}}\end{array}\right]$ where $0_{\mathrm{i}}$ is a zero vector of the $\mathrm{i}^{\text {th }}$ ply;

$\Delta=\left[\left(\Delta_{0}^{(1)}\right)^{\mathrm{T}}\left(\begin{array}{c}\Delta_{1}^{(1)} \\ \Delta_{0}^{(2)}\end{array}\right)^{\mathrm{T}} \cdots\left(\begin{array}{c}\Delta_{1}^{(\mathrm{m}-1)} \\ \Delta_{0}^{(\mathrm{m})}\end{array}\right)^{\mathrm{T}}\left(\Delta_{1}^{(\mathrm{m})}\right)^{\mathrm{T}}\right] ;$

For any ply k of a composite laminate, the solution proposed of the matrix system (2) is written as follow:

$$
\left\{\begin{array}{c}
\Delta_{0}^{(\mathrm{k})} \\
\Delta_{1}^{(\mathrm{k})}
\end{array}\right\}=\mathrm{M}_{\mathrm{q}}^{(\mathrm{k})} \cdot \Delta_{0}^{(\mathrm{k})}
$$

Where

$M_{q}^{(k)}=\left[\begin{array}{c}\mathrm{I} \\ \mathrm{T}_{\mathrm{k}}\end{array}\right]$

$\mathrm{T}_{\mathrm{k}}=\exp \left(\frac{\mathrm{h}_{\mathrm{k}}}{\mathrm{h}} \cdot M_{q}^{(k)}\right)$

The assembling of all plies of the laminate structure gives: 


$$
\Delta=\mathrm{M} \cdot \Delta_{0}
$$

With

$\mathrm{M}=\operatorname{diag}\left[\mathrm{M}_{1} \mathrm{M}_{2} \ldots \mathrm{M}_{\mathrm{m}-1} \mathrm{M}_{\mathrm{m}}\right]$

$\Delta_{0}=\left[\left(\Delta_{0}^{(1)}\right)^{T}\left(\Delta_{0}^{(2)}\right)^{T} \ldots\left(\Delta_{0}^{(m-1)}\right)^{T}\left(\Delta_{0}^{(m)}\right)^{T}\right]^{T} ;$

By substituting the equation (8) into the equation (6) the system bellow (9) is obtained:

$$
\text { J.M. } \Delta_{0}=\mathrm{f}
$$

Finally, the resolution of this system (9) gives all state variables vectors in both superior and inferior faces of each laminate's ply.

\section{Lifetime assessment procedure}

Together to the outputs given by the resolution of a system matrix developed in the previous section, the procedure that we aim to construct in this section is based also on both, a stiffness degradation model (noted SD-M) [25] and an algorithm used for an energy damage prediction model [23].

Stiffness degradation models category is one of the most popular manor to predict damage of structures [4-7, 25-26] which quantify the extent of damage by measuring the Young's modulus of the material. The formula of (10) is used to construct the present procedure:

$$
\frac{\mathrm{k}_{\mathrm{i}}}{\mathrm{k}_{0}}=\mathrm{a}_{2}-\mathrm{a}_{1} \ln \left(\frac{\frac{\mathrm{n}_{\mathrm{i}}}{\mathrm{N}}}{1-\frac{\mathrm{n}_{\mathrm{i}}}{\mathrm{N}}}\right)
$$

Where $\mathrm{a}_{1}$ and $\mathrm{a}_{2}$ are material parameters depending on the ultimate static force $F_{r}$, the stress ratio $r_{i}$ and the minimal force $F_{u}$ for which the failure is not reached.

The second amount on which this procedure depends is an energy approach [23] used to determine two material parameters $\varnothing$ and $\alpha$ of the formula (11) in addition to lifetime at rupture $\mathrm{N}_{\max }$.

$$
\mathrm{N}=\frac{\mathrm{N}_{\max }}{1+\mathrm{e}^{-\varnothing(\Psi+\alpha)}}
$$

Based on this amounts, the algorithm developed of the procedure is scheduled as follow:

- Initially, a Ergodic, Gaussian, Stationary and random loading (noted EGSR) is considered and thanks to algorithm rainflow $[23,25]$ we obtain for each cycle ' $i$ ' the mean value $F_{m, i}$ and the amplitude $F_{a, i}$. These values obtained for an elementary cycle ' $i$ ' are used as inputs of the SSDQM to calculate the six components of displacements and stresses on each point of the discretized laminate. Then, the maximum deflection $\delta_{\max , i}$ resulted on the midle of the laminate is used to assess initial stiffness $\mathrm{k}_{0, \mathrm{i}}$ through expression (12), consequently, the minimal deformation energy of this cycle ' $i$ ' is deduced via expression (13).

$$
\begin{aligned}
& \mathrm{Fa}, \mathrm{i}=\mathrm{k} 0, \mathrm{i} \delta_{\max , \mathrm{i}} \\
& \Psi_{\min , \mathrm{i}}=\frac{\mathrm{F}_{\mathrm{a}, \mathrm{i}}^{2}}{2 \mathrm{k}_{0, \mathrm{i}}}
\end{aligned}
$$

- In the second step, SD-M model (10) is used to find final stiffness $\mathrm{k}_{\mathrm{f}, \mathrm{i}}$ for each cycle ' $\mathrm{i}$ ' which is used to determine the maximal deformation energy (14) of the considered cycle 'i'.

$\Psi_{\text {max }, \mathrm{i}}=\frac{\mathrm{F}_{\mathrm{a}, \mathrm{i}}^{2}}{2 \mathrm{k}_{\mathrm{f}, \mathrm{i}}}$

- Thirdly, we calculate the loading parameter $\mu_{i}$ of each elementary cycle 'i' via expression (15). Therefore, by using the energy approach [23] the material parameters $\emptyset_{i}$ and $\alpha_{i}$ as well as the rupture lifetime $\mathrm{N}_{\mathrm{i}}$

$$
\mu_{\mathrm{i}}=\mathrm{r}_{, \mathrm{i}} * \frac{\mathrm{F}_{\mathrm{m}, \mathrm{i}}}{\mathrm{F}_{\text {max }, \mathrm{i}}}
$$

- Finally, the well-known Palmgreen-Miner rule [24] is adopted to predict lifetime of the composite laminate examined: 
$\mathrm{T}=\frac{1}{\sum \frac{\mathrm{n}_{\mathrm{i}}}{\mathrm{N}_{\mathrm{i}}}}$
To sum-up, figure (Fig. 1) show clearly the steps of the procedure developed above.

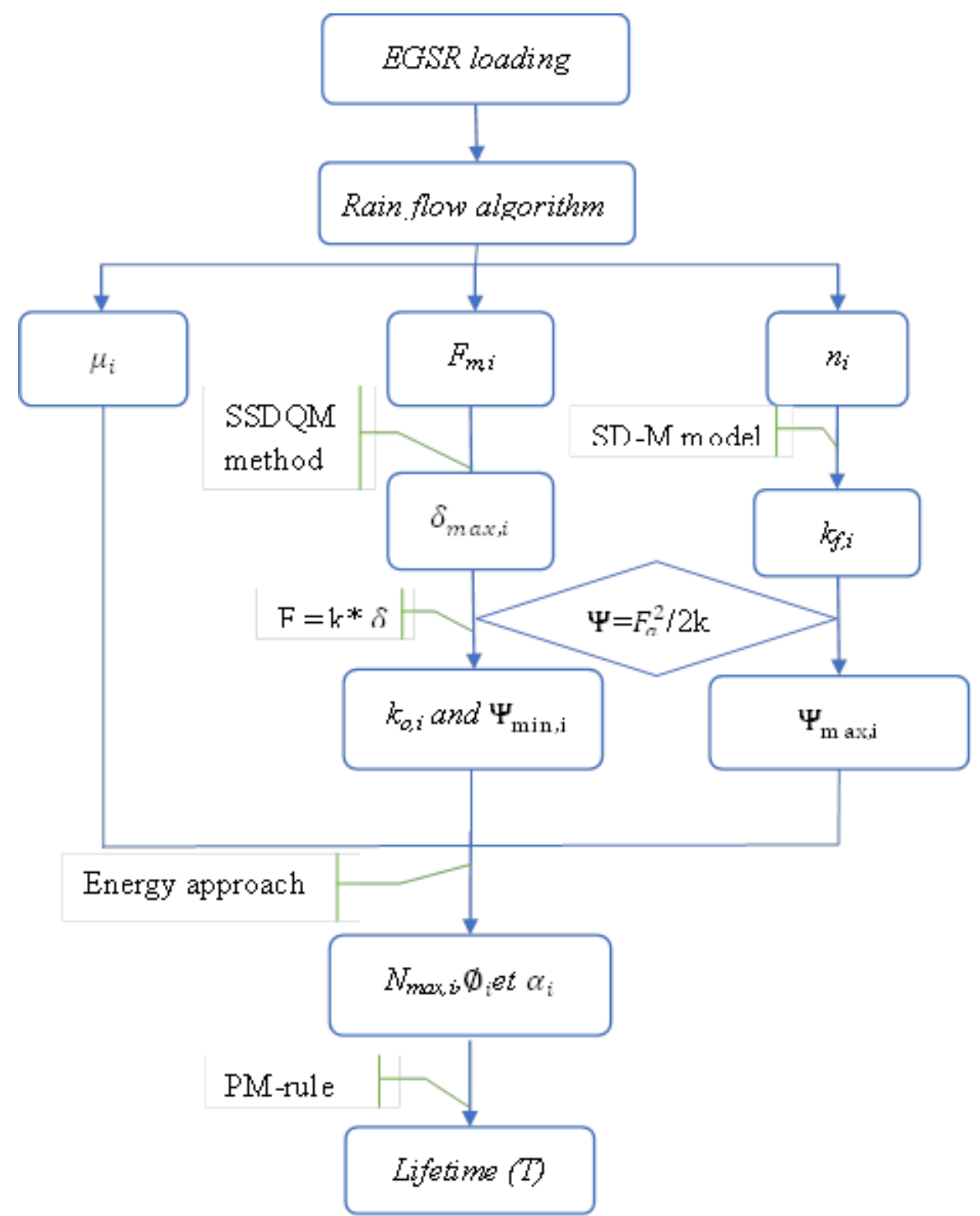

Fig. 1. Hybrid procedure for damage prediction of a composite laminate.

\section{Results and discussions}

The material used for the experimental study is a quasi-isotropic graphite/epoxy composite laminate $[45 / 0 / 90]_{3 S}$ and the tests on which we based were performed by MTS 810 servo-hydraulic machine [25, 27]. Two variable amplitude fatigue experiments are conducted where four specimens are tested for each experimental case defined by the mean value $\mathrm{F}_{\mathrm{m}}$ and the standard deviation $\sigma$ of the loading.
In order to validate the procedure developed in this work, two EGSR loadings were simulated identically to the experimental ones [25, 27]. In the first case, the mean value of a loading is $\mathrm{Fm}=2000$ $\mathrm{N}$ and its standard deviation is $\sigma=500 \mathrm{~N}$, while in the second case the mean value and the standard deviation taken are $\mathrm{F}_{\mathrm{m}}=1500 \mathrm{~N}$ and $\sigma=350 \mathrm{~N}$ respectively. Experimental lifetimes are given in Table 1 together with our model predictions and some model results of the literature [23, 25, 27-28]. 
Table 1 Comparison between hybrid model predictions, experimental lifetimes and some literature's models.

\begin{tabular}{|c|c|c|}
\hline \multirow{2}{*}{ Lifetime (in cycles) } & Loading 1: & Loading 2: \\
\hline Experimental test [25] & $\mathrm{F}_{\mathrm{m}=2000(\mathrm{~N}) ; \sigma=500(\mathrm{~N})}$ & $\mathrm{F}_{\mathrm{m}}=1500(\mathrm{~N}) ; \sigma=350(\mathrm{~N})$ \\
\hline Energy model [23] & 4410 & 54517,5 \\
\hline Statistical model [27] & 6504,9 & 57909 \\
\hline Stiffness degradation model [25] & 5900 & 58700 \\
\hline Niesloney's first model [28] & 5100 & 52300 \\
\hline Niesloney's second model [28] & 1800 & 3000 \\
\hline Proposed hybrid procedure & 3700 & 38000 \\
\hline
\end{tabular}

Hybrid procedure predictions are quite identical to energy model [23] results and are very close to both, statistical model [27] and stiffness degradation model [25] ones. Niesloney's models [28] are too divergent in comparison with experimental tests [25] and with all models presented in the table 1.

On the other side, we remark that the difference rate between our procedure predictions and experimental lifetimes is very acceptable, especially for the second experiment which doesn't exceed 5 percent whereas in the first experiment this rate is quite higher. So despite that, all other models are also in the same order of magnitude as our hybrid model, but this difference can be explained from the fact that all these models used a linear cumulative damage rule to assess lifetimes which doesn't take into account the load sequence and interaction effects.
Space state differential quadrature method is solved with a new technic, a series of stresses and deformations are obtained for each load's cycle. The SSDQM is usually used to analyze free vibration behavior of different composite structures, in this work it was exploited in conjunction with one damage prediction model namely stiffness degradation model (SD-M model) and an energetic approach to predict damage rupture of a composite laminate.

A satisfactory convergence of this hybrid procedure is verified through numerical comparison with other numerical models and also versus experimental tests. Hence, this procedure presents an ambition solution to monitor and predict damage evolution inside the laminate.

\section{Appendix A:}

- Clamped - Clamped (CC) :

\section{Conclusion}




$$
\begin{aligned}
\mathrm{M}_{1 \mathrm{q}}^{(\mathrm{k})}=\left[\begin{array}{ccc}
-\rho \omega^{2} I_{N-2}-\frac{1}{c_{7}} f_{C C} & -g_{C C}^{(1)} & \lambda_{b} I_{N-2} \\
-g_{C C}^{(1)} & c_{7} I_{N-2} & 0 \\
-\lambda_{b} I_{N-2} & 0 & c_{8} I_{N-2}
\end{array}\right], \\
\mathrm{M}_{2 \mathrm{q}}^{(\mathrm{k})}=\left[\begin{array}{ccc}
c_{9} I_{N-2} & c_{1} g_{C C}^{(1)}\left(c_{6} \lambda_{b}^{2}-\rho \omega^{2}\right) I_{N-2} & -c_{5} \lambda_{b} I_{N-2} \\
c_{1} g_{C C}^{(1)} & -c_{2} g_{C C}^{(2)}-\frac{c_{1}^{2}}{c_{9}} f_{C C} & \left(c_{3}+c_{6}\right) \lambda_{b} g_{C C}^{(1)} \\
c_{5} \lambda_{b} I_{N-2} & -\left(c_{3}+c_{6}\right) \lambda_{b} g_{C C}^{(1)} & \left(c_{4} \lambda_{b}^{2}-\rho \omega^{2}\right) I_{N-2}-c_{6} g_{C C}^{(2)}
\end{array}\right],
\end{aligned}
$$

- $\quad$ Clamped - Simply support (CS) :

The elements $f_{C C}, g_{C C}^{(1)}$ and $g_{C C}^{(2)}$ are expressed as following:

$f_{C C i j}=g_{i 1}^{(1)} g_{1 j}^{(1)}+g_{i N}^{(1)} g_{N j}^{(1)}$

$$
\mathrm{M}_{1 \mathrm{q}}^{(\mathrm{k})}=\left[\begin{array}{ccc}
-\rho \omega^{2} I_{N-2}-\frac{1}{c_{7}} f_{1 C S} & -g_{C S}^{(1)} & \lambda_{b} I_{N-2} \\
-\left[g_{C S}^{(1)}\right]^{T} & c_{7} I_{N-1} & 0 \\
-\lambda_{b} I_{N-2} & 0 & c_{8} I_{N-2}
\end{array}\right] \text {, }
$$

$g_{C C i j}^{(r)}=w_{i j}^{(r)} \quad(\mathrm{i}, \mathrm{j}=2,3, \ldots, \mathrm{N}-1)$ and $(\mathrm{r}=0$ or 1$)$.

$$
\begin{aligned}
& \mathrm{M}_{2 \mathrm{q}}^{(\mathrm{k})}=\left[\begin{array}{ccc}
c_{9} I_{N-2} & c_{1} g_{C S}^{(1)}\left(c_{6} \lambda_{b}^{2}-\rho \omega^{2}\right) I_{N-1} & -c_{5} \lambda_{b} I_{N-2} \\
c_{1}\left[g_{C S}^{(1)}\right]^{T} & c_{2} h-\frac{c_{1}^{2}}{c_{9}} f^{\prime}{ }_{1 C S} & \left(c_{3}+c_{6}\right) \lambda_{b}\left[g_{C S}^{(1)}\right]^{T} \\
c_{5} \lambda_{b} I_{N-2} & -\left(c_{3}+c_{6}\right) \lambda_{b} g_{C S}^{(1)} & \left(c_{4} \lambda_{b}^{2}-\rho \omega^{2}\right) I_{N-2}-c_{6} g_{C S}^{(2)}
\end{array}\right] \text {, } \\
& {f^{\prime}}^{\prime}{ }_{C S i j}=g_{i 1}^{(1)} g_{1 j}^{(1)} \quad(i, j=2,3, \ldots, N),
\end{aligned}
$$

Where :

$h={f^{\prime}}_{N C S}-g_{C S}^{(2)}$ $g_{C S i j}^{(1)}=w_{i j}^{(1)}(i=2,3, \ldots, N-1$ and $j=2, \ldots, N)$.

$f_{1 C S i j}=g_{i 1}^{(1)} g_{1 j}^{(1)} \quad(i, j=2,3, \ldots, N-1)$,

- Simply support - Simply support (SS) :

$g_{C S}^{(2)}=g_{C C}^{(2)}$

$$
\mathrm{M}_{1 \mathrm{q}}^{(\mathrm{k})}=\left[\begin{array}{ccc}
-\rho \omega^{2} I_{N-2} & -g_{S S}^{(1)} & \lambda_{b} I_{N-2} \\
-\left[g_{S S}^{(1)}\right]^{T} & c_{7} I_{N-2} & 0 \\
-\lambda_{b} I_{N-2} & 0 & c_{8} I_{N-2}
\end{array}\right] \text {, }
$$

$$
{f^{\prime}}^{\prime}{ }_{N S i j}=g_{i N}^{(1)} g_{N j}^{(1)}, \quad g_{C S i j}^{\prime(2)}=w_{i j}^{(2)},
$$

$$
\mathrm{M}_{2 \mathrm{q}}^{(\mathrm{k})}=\left[\begin{array}{ccc}
c_{9} I_{N-2} & c_{1} g_{S S}^{(1)} & -c_{5} \lambda_{b} I_{N-2} \\
c_{1}\left[g_{S S}^{(1)}\right]^{T} & \left(c_{6} \lambda_{b}^{2}-\rho \omega^{2}\right) I+c_{2}\left(f-g^{(2)}\right) & \left(c_{3}+c_{6}\right) \lambda_{b}\left[g_{S S}^{(1)}\right]^{T} \\
c_{5} \lambda_{b} I_{N-2} & -\left(c_{3}+c_{6}\right) \lambda_{b} g_{S S}^{(1)} & \left(c_{4} \lambda_{b}^{2}-\rho \omega^{2}\right) I_{N-2}-c_{6} g_{S S}^{(2)}
\end{array}\right],
$$

$$
g_{S S i j}^{(1)}=w_{i j}^{(1)}(i=2,3, \ldots, N-1 \text { and } j=1, \ldots, N),
$$

Where

$$
f_{S S i j}=g_{i 1}^{(1)} g_{1 j}^{(1)}+g_{i N}^{(1)} g_{N j}^{(1)} \quad(i, j=1,2, \ldots, N),
$$

$$
g_{S S}^{(2)}=g_{C C}^{(2)},
$$

- $\quad$ Clamped - Free (CF) : 
$\begin{aligned} \mathrm{M}_{1 \mathrm{q}}^{(\mathrm{k})} & =\left[\begin{array}{ccc}-\rho \omega^{2} E_{1}-f_{1 C F} & -g_{1 C F}^{(1)} & \lambda_{b} E_{1} \\ -g_{2 C F}^{(1)} & c_{7} I_{N-2} & 0 \\ -\lambda_{b} I_{N-1} & 0 & c_{8} I_{N-1}\end{array}\right], \\ \mathrm{M}_{2 \mathrm{q}}^{(\mathrm{k})} & =\left[\begin{array}{ccc}c_{9} E_{2} & M_{2,12} & M_{2,13} \\ c_{1}\left[g_{1 C F}^{(1)}\right]^{T} & M_{2,22} & M_{2,23} \\ c_{5} \lambda_{b} E_{2} & M_{2,32} & M_{2,33}\end{array}\right],\end{aligned}$

Where

$$
\begin{aligned}
& M_{2,12}=c_{1}\left[g_{2 C F}^{(1)}\right]^{T}+\frac{c_{2} c_{9}}{c_{1}} E_{3}, \\
& M_{2,13}=-\frac{c_{1}}{\lambda_{b}} f_{N C F}-c_{5} \lambda_{b} I_{N-1}-\frac{c_{2} c_{9}}{\lambda_{b} c_{1}} E_{4}, \\
& M_{2,22}=\left(c_{6} \lambda_{b}^{2}-\rho \omega^{2}\right) I_{N-2}+c_{2}\left(f_{C F}-g_{C F}^{(2)}\right), \\
& M_{2,23}=\left(c_{3}+c_{6}\right) \lambda_{b} g_{2 C F}^{(1)}+\frac{c_{2}}{\lambda_{b}}\left(\bar{f}_{N C F}-f_{N C F}^{*}\right), \\
& M_{2,32}=-\left(c_{3}+c_{6}\right) \lambda_{b}\left[g_{2 C F}^{(1)}\right]^{T}+\frac{c_{2} c_{5}}{c_{1}} \lambda_{b} E_{3}, \\
& M_{2,33}=\left(c_{3}+c_{6}\right) f_{N C F}+\left(c_{4} \lambda_{b}^{2}-\rho \omega^{2}\right) I_{N-1} \\
& \quad-c_{6} g_{C F}^{\prime(2)}-\frac{c_{2} c_{5}}{c_{1}} E_{4} .
\end{aligned}
$$$$
E_{1}=\left[\begin{array}{cc}
0 & 0 \\
I_{N-2} & 0
\end{array}\right], \quad E_{2}=\left[\begin{array}{cc}
0 & I_{N-2} \\
0 & 0
\end{array}\right],
$$$$
E_{3}=\left[\begin{array}{c}
0_{(N-2) x(N-2)} \\
\alpha_{g}
\end{array}\right], \quad E_{4}=\left[\begin{array}{c}
0_{(N-2) x(N-1)} \\
\alpha_{f N}
\end{array}\right],
$$$$
f_{1 C F i j}=g_{i 1}^{(1)} g_{1 j}^{(1)} \quad(i=1,2 \ldots, N-1 \text { and } j
$$$$
=2,3, \ldots, N) \text {, }
$$$$
g_{1 C F i j}^{(1)}=w_{i j}^{(1)} \quad(i=1,2, \ldots, N-1 \text { and } j
$$$$
=2,3, \ldots, N-1) \text {, }
$$$$
g_{2 C F i j}^{(1)}=w_{i j}^{(1)}, \quad \bar{f}_{N i j}=g_{N 1}^{(2)} g_{N j}^{(1)},
$$$$
f_{N i j}^{*}=g_{i N}^{(1)} g_{N N}^{(1)} g_{N j}^{(1)}(i=2, \ldots, N-1 \text { and } j
$$$$
=2,3, \ldots, N) \text {, }
$$$$
f_{N C F i j}=g_{i N}^{(1)} g_{N j}^{(1)} \quad(i, j=2,3, \ldots, N),
$$

$$
\begin{aligned}
& \alpha_{g}=\left[\begin{array}{llll}
g_{N 2}^{(1)} & g_{N 3}^{(1)} & \ldots & g_{N(N-1)}^{(1)}
\end{array}\right], \\
& \alpha_{f N}=\left[\begin{array}{llll}
g_{N 2}^{(1)} & g_{N 3}^{(1)} & \ldots & g_{N N}^{(1)}
\end{array}\right], \\
& f_{C F}=f_{C C}, \quad g_{C F}^{(2)}=g_{C C}^{(2)}, \\
& f_{N C F}=f^{\prime}{ }_{N C S}, \quad g_{C F}^{(2)}=g_{C S}^{(2)} .
\end{aligned}
$$

\section{References:}

[1] W.X. Yao, N. Himmel, A new cumulative fatigue model for fiber-reinforced plastics, Compos. Sci. Technol. 60 (2000) 59-64.

[2] J. Aghazadeh Mohandesi, B. Majidi, Fatigue damage accumulation in carbon/epoxy laminated composites, Mater. Des. 30 (2009) 1950-1956.

[3] F. Wu, W. Yao, A fatigue damage model of composite materials, Int. J. Fatigue 32 (1) (2010) 134-138.

[4] Y.-M. Jen, Y.-H. Yang, A study of two-stage cumulative fatigue behavior for CNT/ epoxy composites, Procedia Engineering 2 (1) (2010) 2111-2120.

[5] R.B. Toumi, J. Renard, M. Monin, P. Nimdum, Fatigue damage modelling of continuous E-glass fibre/epoxy composite, Procedia Engineering 66 (2013) 723-736.

[6] W. Zhang, Z. Zhou, B. Zhang, S. Zhao, A phenomenological fatigue life prediction model of glass fiber reinforced polymer composites, Mater. Des. 66 (2015) 77-81.

[7] S. Shiri, M. Yazdani, M. PourgolMohammad, Fatigue life prediction of polymeric composites based on the simultaneous degradation of stiffness and strength under two-stage loading, Modares Mechanical Engineering 14 (14) (2015) 137142 (In Persian). 
[8] H. Mao, S. Mahadevan, Fatigue damage modelling of composite materials, Compos. Struct. 58 (4) (2002) 405-410.

[9] K.-W. Kang, D.-M. Lim, J.-K. Kim, Probabilistic analysis for the fatigue life of carbon/ epoxy laminates, Compos. Struct. 85 (3) (2008) 258-264.

[10] S. Shiri, M. Pourgol-Mohammad, M. Yazdani, Prediction of Remaining Fatigue Cycles in Composite Materials Under Uncertainty, ASCE-ASME Journal of Risk and Uncertainty in Engineering Systems, Part B, Mechanical Engineering, 2015http://dx.doi. org/10.1115/1.4031037.

[11] T. Peng, Y. Liu, A. Saxena, K. Goebel, Insitu fatigue life prognosis for composite laminates based on stiffness degradation, Compos. Struct. 132 (2015) 155-165.

[12] R. Bellman, BG. Kashef, J. Casti. Differential quadrature: a technique for the rapid solution of non-linear partial differential equations. $\mathbf{J}$ Comput Phys; 10 (1972) : 40-52.

[13] CW. Bert, SK. Jang, AG. Striz. Nonlinear bending analysis of orthotropic rectangular plates by the method of differential quadrature. Comput Mech; 5 (1989) : $217-$ 226.

[14] CW. Bert, M. Malik. Transient analysis of gas- ubricated journal bearing systems by differential quadrature. ASME J Tribol; 119 (1997) :91-99.

[15] WQ. Chen, CF. Lv, ZG. Bian. Elasticity solution for free vibration of laminated beams. Compos Struct; 62 (2003) : 75-82.

[16] C. Shu, BE. Richards. Application of generalized differential quadrature to solve two-dimensional incompressible. Navier-
Stokes equations. Int J Numer Meth Fluids; 15 (1992): 791-8.

[17] W.Q. Chen, C.F. Lue. 3D free vibration analysis of cross-ply laminated plates with one pair of opposite edges simply supported. Comp Struct; 69 (2005): 77-87.

[18] LY. Bahar. Transfer matrix approach to layered systems. J Eng Mech; 98 (1972): 1159-72.

[19] WQ Chen, JB Cai and Ye GR. Exact solutions of cross-ply laminates with bonding imperfections. AIAA J; 41 (2003): 2244-50.

[20] WQ Chen, KY Lee. Three-dimensional exact analysis of angle-ply laminates in cylindrical bending with interfacial damage via state space method. Compos Struct; 64 (2004): 275-83.

[21] WQ Chen WQ, CF Lüe. 3D free vibration analysis of cross-ply laminated plates with one pair of opposite edges simply supported. Compos Struct; 69 (2005): 77-87.

[22] Xu Rongqiao, $\mathrm{H}$ Ding. Two-dimensional solutions for orthotropic materials by the state space method. Compos Struct; 78 (2007): 325-336.

[23] B. Mohammed, A. Mohamed and O. Brahim. Fatigue life prediction of composite laminate under random loading service: An energy approach. Materials Today: Proceedings. https://doi.org/10.1016/j.matpr.2020.05.091.

[24] Yung-Li Lee, Tana Tjhung, Chapter 3 Rainflow Cycle Counting Techniques. Metal Fatigue Analysis Handbook 2012, pp. 89-114.

[25] M. BOUSFIA et al. fatigue life prediction for composite materials under Ergodic Gaussian and Stationary Random (EGSR) loads. 
Composites: Mechanics, Computations, Applications: An International Journal; 2017; DOI:10.1615/CompMechComputApplIntJ.v8. i3.10.

[26] A. Shirazi, A. Varvani-Farahani, A stiffness degradation based fatigue damage model for FRP composites of $(0 / \theta)$ laminate systems, Appl. Compos. Mater. 17 (2) (2010) $137-$ 150.

[27] M. Aboussaleh, R. Boukhili. Life prediction for composite laminates submitted to service loading spectra. Polym. Compos. 19 (1998) 241-245.

[28] A. Niesloney, M. Böhom, Mean stress effect correction using constant stress ratio S-N curves, Int. J. Fatigue (2013), https://doi.org/10.1016/j.

ijfatigue.2013.02.2019.

\section{Contribution of individual authors to the creation of a scientific article}

Mohammed BOUSFIA: software, formal analysis, methodology and investigation.

Mohamed ABOUSSALEH: supervision, project administration and methodology.

Brahim OUHBI: validation and visualization.

\section{Creative Commons Attribution}

\section{License 4.0 (Attribution 4.0 \\ International , CC BY 4.0)}

This article is published under the terms of the Creative Commons Attribution License 4.0 https://creativecommons.org/licenses/by/4.0/deed.en US 